\title{
The Effects of a Health-Based Context on Memory for Advertisements
}

\author{
Sundus Mahdi ${ }^{1}$, Adrian Furnham ${ }^{1,2}$ \\ ${ }^{1}$ Research Department of Clinical, Educational and Health Psychology, University College London, London, UK \\ ${ }^{2}$ Norwegian Business School (BI), Olso, Norway \\ Email: a.furnham@ucl.ac.uk
}

Received 2 July 2016; accepted 19 July 2016; published 22 July 2016

Copyright (C) 2016 by authors and Scientific Research Publishing Inc.

This work is licensed under the Creative Commons Attribution International License (CC BY).

http://creativecommons.org/licenses/by/4.0/

(c) $\underset{\mathrm{Br}}{\mathrm{gr}}$ Open Access

\begin{abstract}
This study looked at whether heath-based advertisements were remembered when placed in a health (congruity) or non-health (incongruity) based television programme and the extent to which participant involvement influenced recall. The study aimed to test whether programme context had an effect on memory for congruent or incongruent advertisements. Sixth-form students watched either a health or non-health programme, with health or non-health centre-break advertisements. Sessions took place during the morning and afternoon. Free recall and cued recall tests were administered to test memory for the TV adverts. Results found no support for the cognitive priming theory, cognitive interference theory or for contrast effects. The study found little evidence to support any theory as to why programme surround should influence the recall of health advertisements. Limitations of the study are considered.
\end{abstract}

\section{Keywords}

Television Advertisements, Time of Day, Context, Congruency

\section{Introduction}

\subsection{Advertisement-Programme Congruity}

A vast amount of research has looked into the effects of advertisement-programme congruity upon memory (Gunter, Baluch, Duffy, \& Furnham, 2002; Furnham, Bergland, \& Gunter, 2002a; Furnham, Gunter, \& Richardson, 2002b; De Pelsmacker, Geuens, \& Anckaert, 2002). These tested whether memory for advertisements was strengthened when embedded within a programme that was congruent in content (Bushman \& Bonacci, 2002; Furnham, Gunter, \& Walsh, 1998; Furnham \& Mainaud, 2010) or products displayed (Furnham et al., 2002a). 


\subsubsection{Congruity Facilitates Memory}

Some studies have shown that when an advertisement and programme are both congruent in content, memory for the centre-break advertisements are remembered hence recalled better. This is supported by the cognitive priming theory (Sanbonmatsu \& Fazio, 1991). Gunter, Furnham and Pappa (2005) found that memory for violent adverts were enhanced when embedded within a violent film, in comparison to non-violent adverts. The contents within the programme will work as a prime for any similar relations displayed in the proceeding advertisement. Hence, a prime from the programme will trigger representations in memory, leaving them active short-term. This in turn will facilitate the comprehension of subsequent similar material displayed from the advertisements and will strengthen the encoded message.

Following on from this, the model of construct accessibility theory claims that semantic memory is organised in such a way that it is formed from many networks. The networks contain nodes that in turn represent constructs, which interlink and produce pathways of association between one another. Inter-connections represent similarities between different representations or ideas, such as congruity and similarity (Bryant \& Zillmann, 1994). Hence, when one node is activated, such as a product in a programme, it triggers off an activation circuit, in which all similar constructs also become activated between memory networks. This is the cause of priming. Not only does context congruity have a positive effect on memory, but it has also been found to have a positive effect on affect and has led to greater understanding of the advertisements presented (De Pelsmacker et al., 2002). Furthermore, congruity also had a positive effect on advert evaluation, in which "happy adverts" and "sad adverts” were perceived more favourably when embedded within "happy programmes” and "sad programmes”, respectively (Kamins, Marks, \& Skinner, 1991). This is in line with the affect transfer hypothesis, which states that the positive or negative vibe transmitted from the programme is likely to over-run onto the consecutive adverts; hence a misattribution error will occur (De Pelsmacker et al., 2002).

\subsubsection{Incongruity Facilitates Memory}

Memory for advertisements may be improved when there is programme-advert incongruity. For example, Furnham et al. (1998) found that humorous adverts were best remembered when embedded within a non-humorous context, in comparison to non-humorous adverts. The cognitive interference theory explains this phenomenon. When a programme and a proceeding advert share similar meaning, features or content (Bryant \& Zillmann, 1994), meltdown occurs, in which overlapping elements and representations begin to merge together. This will have a detrimental effect on memory, hence impairing recall. It was found that advertisements for cars were better remembered when placed in a food-based programme (e.g., Real Food with Nigel Slater) than if food adverts were placed in a food-based cooking programme (Furnham et al., 2002b).

Proactive interference causes people to forget knowledge and ideas that have been learned recently because of interference from old memories. On the other hand, retroactive interference occurs when recently learned infomation makes the mind forget previously learned information. Proactive interference and retroactive interference will occur when the "to be remembered" material (e.g., adverts) are preceded or followed by material of similar content, respectively. Interference will cause a memory impairment for the "to be remembered” material. Gunter, Clifford and Berry (1980) had participants view an array of news items. Memory for a preceding news item had detrimental effects for memory on subsequent news items, when these items were similar in content. This decline in memory was strengthened the more news items were present, supporting the theory of proactive interference.

Similarly, the contrast effect is also used to explain improved memory for advertisements placed in an incongruent context (Meyers-Levy \& Tybout, 1997). When the advertisement message contrasts with its context in terms of novelty and innovation, it stands out, increases one's attention, and increases interest (Goodstein, 1993). Furthermore, Juntunen (1995) found that greater attention is enthused when an advertisement is placed in a contrasting context.

According to the von Restorff phenomenon of the isolation effect, distinctiveness is a crucial aspect for memory empowerment. If there is dissimilarity found between the advertisement and its context, the advertisement will be perceived as more distinctive, which in turn will stand out, and will be remembered better (Hunt, 1995).

Some research has found both priming and interference effects. Furnham et al. (2002a) tested viewers' memory for a beer advertisement. The context in which this advertisement was viewed varied amongst conditions. The beer drinking scenes appeared either; before and after the centre break advertisements, before or after the centre break advertisements, or there was no drinking scene at all. Results showed better memory for the beer 
advertisement when the drinking scene was placed after the centre-break, also known as a backward priming effect. However, there was poorer memory for the beer advertisement when the drinking scene was located directly before the advertisement, depicting a cognitive interference effect.

\subsection{Programme-Induced Involvement}

It has been theorised that memory for advertisements are hindered when they are embedded within a highly involving programme (Norris \& Colman, 1992). According to Howard (1977) this is due to the viewer's annoyance that they have been interrupted from viewing the involving programme. However, Norris and Colman (1993) argued for a limited information processing capacity. This causes difficulties in switching one's attention away from the involving events within the programme, onto the proceeding advertisements, which in turn will impair recall. On the other hand, facilitative priming suggests that involving programmes set a scene in which viewers' attention increases, therefore allowing this highly attentive state to carry on through the advertisements, improving memory for the advertisements (Norris \& Colman, 1993).

\subsection{Health Advertisements}

The rise of obesity worldwide has raised great concern. Figures show a drop in a healthy Body Mass Index (18.5 - 24.9) between 1993 and 2010, in which the prevalence of obesity in England has tripled in the last 25 years. Figures from 2010 show 26.1\% of all adults and 16\% of all children were obese (Hirani, 2010; Bridges \& Thompson, 2010).

Research has shown increased association between obesity and TV viewing habits; especially where advertisements are concerned (Dixon, Scully, Wakefield, White, \& Crawford, 2007; Hancox, Milne, \& Poulton, 2004; Viner \& Cole, 2005). For example, research has shown that food-based adverts increase preference and purchasing behaviour for the products advertised (Hastings et al., 2003). Furthermore, Gorn and Goldberg (1982) conducted a study which investigated the effects of food advertising on children. Subjects were exposed to a daily cartoon, for the duration of two weeks, with candy or fruit advertising, Public Service Announcements (PSAs), or no adverts. Results found that children exposed to the candy adverts were less inclined to choose fruit and orange juice as a snack in comparison to children in the other conditions. These results reflect on the negative consequences of watching non-nutritional food advertising, rather than the positive consequences of healthy food ads. These studies suggest the impacts of advertising as a "real-world" prime, where one is drawn to certain behaviours promoted during advertisements automatically without conscious awareness. For instance, when one is exposed to aggressive or alcohol-consuming scenes within the media, this may later act as a prime for aggressive behaviours and alcohol consumption by the viewer (Anderson \& Bushman, 2002).

If research has shown that adverts demonstrate a "real-life" prime, then perhaps pro-health adverts can have positive results on pro-health behaviours. Harris, Bargh and Brownell (2009) conducted a study in which adults viewed a TV programme with centre break advertising promoting either snacking, benefits of nutrition, or no food advertisements. Subjects were soon after given the opportunity to taste an array of healthy and unhealthy snacks. Results found that healthy snacking adverts had no effect on food consumption behaviour; however non-healthy ads increased both calorific snack consumption and healthy snacking. Hence, it may be a possibility that unhealthy food advertising is more susceptible to priming effects than healthy food advertising, in which the latter will be less likely to "stick" in memory. As has been previously stated, context effects have before shown to have a positive impact on memory for advertisements (Furnham et al., 2002a; Gunter et al., 2005). However, never has the context of health been explored before within this line of research. Therefore, in this study we would like to test the effects of a health context, on memory for health advertisements, comprising of a mix of healthy food-consumption and pro-health behaviours.

The present study investigated whether programme-advertisement congruity had an effect upon immediate memory recall. Programme-advert congruity possessed a "health and fitness" theme, which overlaps with both broad content and product context effects. A mixed model ANOVA comprising of a $2 \times 2$ factorial design was planed. This encompassed two between-subject variables: programme-type (health and fitness vs. non-health and fitness), and advert-type (health and fitness vs. non-health and fitness), and one within-subjects variable: memory test type (free recall vs. cued recall).

H1: Memory for centre-break advertisements will be reinforced when the adverts are congruent with the main themes displayed in the television programme, in comparison to if the themes are incongruent. This hypothesis 
is supported by the cognitive priming theory, construct accessibility theory and affect transfer hypothesis.

H2: Memory for centre-break advertisements will be reinforced when the adverts are incongruent with the main themes displayed in the television programme, in comparison to if the themes are congruent. This hypothesis is supported by the cognitive interference theory, the von Restorff isolation effect and contrast effects.

H3: High programme involvement will have a negative impact on memory for television advertisements.

\section{Method}

\subsection{Participants}

The participants were in total 160 AS-Level psychology students recruited from a sixth form college in West Yorkshire. Eleven participants were discarded from the data before analysis, primarily due to having seen one of the centre-break advertisements before, whilst one subject was also discarded for not following instructions properly. This left us with 149 subjects (45 males and 104 females) with a mean age of 17 years $(S D=.56)$.

Participants were randomly allocated to either one of four conditions: Group One $(\mathrm{N}=40)$ - Health Programme with health advertisements; Group Two ( $\mathrm{N}=39)$ - Health Programme with non-health advertisements; Group Three $(\mathrm{N}=36)$-Non-health programme with health advertisements; Group Four $(\mathrm{N}=34)$-Non-health programme with non-health advertisements.

Subjects were placed in their given conditions according to the psychology class they were in at school, though the distribution of classes into their conditions was randomly assigned. Subjects varied in ethnicity, though the dominant ethnic background was 63.1\% White British, followed by 12.1\% Asian and 4.7\% Black African. All were fluent English speakers.

In total, 63.8\% reported having a TV in their bedroom, $41.6 \%$ reported having watched the TV show presented in the past, though none had seen the same episode broadcasted, and the modal group for the amount of TV watched weekly was 10 hours, though this ranged from 0 - 65 hours. Analysis will take this into consideration.

\subsection{Materials}

\subsubsection{Programmes}

Four mpeg. movie files were created using Windows Movie Maker, which comprised of approximately 30 minutes of an episode, including approximately three minutes of the edited centre-break embedded nearly half-way through the footage. The episodes watched were either "The Biggest Loser" for the Health and Fitness condition, or "The Apprentice Australia" for the non-health condition. Both programmes were of a reality-TV nature. These episodes were aired approximately 11 months and 1 year 11 months before the experiment was carried out, respectively. “The Biggest Loser” episode comprised of a group of competitors whom were all over-weight. They faced a "cup cake challenge”, were taught how to bake low-fat cupcakes, and were seen participating in an extensively intense work-out gym session. "The Apprentice Australia” episode comprised of a group of competitors who had to design the packaging for children's cereal. They had to think of a name, a design, and a jingle for their product.

\subsubsection{Advertisements}

The two sets of advertisement breaks were health and fitness related, and non-health and fitness related. These were edited as centre-break advertisements, into the above mentioned episodes. Each centre-break advertisement consisted of six, approximately 30 seconds long, adverts, making a collection of 12 adverts in total. These 12 adverts were selected from an array of 34. A pilot study comprising of 10 subjects completed an advertisementratings questionnaire. They were given eight dimensions (funny, sad, entertaining, violent, involving, familiarity, gender bias, and fits into the theme of health and fitness), in which they had to rate their agreeability using a 7-point bipolar scale. Numerous $t$-tests were carried out to select six health and fitness and six non health and fitness adverts that did not differ significantly on all of these dimensions. The health and fitness related adverts selected were: Jenny Craig weight loss plan (length: 29 seconds), Bob Harper's Smart Weight Loss Starter Kit (length: 30 seconds), Fitness First jobs (length: 31 seconds), Mobia by Nautilus work out machine (length: 25 seconds), Slim Fast snack bars (length: 30 seconds), and Goodlife Gym (length: 31 seconds). The non-health and fitness adverts selected were: BMW cars (length: 30 seconds), Blundstone boots (length: 32 seconds), Karcher Patio Cleaner (length: 30 seconds), Ikea Catalogue (length: 29 seconds), Suncorp Bank (length: 30 seconds) and Sony Ericsson exclusive to Vodafone mobile (length: 30 seconds). 


\subsection{Questionnaires}

\subsubsection{Mood State Ratings}

Subjects were given the same mood questionnaire before and after viewing their allocated programme. Questionnaires asked subjects to describe how they were feeling right now on 14 dimensions, each on a 5-point scale, ranging from "not at all" to "extremely". Eight items were gathered from the Profile of Mood States (POMS; alert, angry, clear-headed, nervous, unable to concentrate, sad, forgetful, and relaxed; McNair, Lorr \& Doppelman, 1971) whilst five were gathered from the Positive and Negative Affect Schedule Expanded Form (PANAS-X; afraid, upset, enthusiastic, tired, and distressed; Watson \& Clark, 1999). The final dimension was chosen by the experimenter (content). The data were later discarded from analysis.

\subsubsection{Memory for Advertisements}

Memory for advertisements was tested using two methods.

1) Free recall. Subjects had three minutes to write down the names of all six products and brands advertised in the centre-break of their viewed programme, from memory. This was provided in a table format, working as a cue to prompt memory recall. Recall was not asked in any particular order.

2) Cued recall. Subjects were provided with the brand name of each product advertised, along with three multiple choice questions. A choice of one answer, out of four, per question was required. Which 18-item Multiple Choice Questionnaire (MCQ) was assigned was dependent upon subjects’ allocated condition.

\subsubsection{Programme Evaluation}

Subjects were given two minutes to complete a programme-ratings evaluation questionnaire. This comprised of fourteen 7-point bipolar adjective scales (humour, amusing, enjoyable, entertaining, cheerful, happy, interesting, absorbing, stimulating, exciting, thought-provoking, involving, complicated and engaging) to describe the programme viewed (Furnham et al., 2002b).

\subsubsection{Personal Details}

Three minutes were allocated to provide demographics and background information regarding TV viewing habits and health related behaviours.

\section{Results}

Statistical Methods: The primary analysis involved a number of analyses of variance to test the various hypotheses.

\subsection{Programme-Advert Content on Memory for Advertisements}

A two-way mixed ANOVA was computed to test the main effects of Programme (Health vs. non-Health) and Advertisement (Health vs. non-Health) on memory for advertisements (Free recall vs. Cued recall). See Table 1 for means and standard deviations.

Tests of within-subjects effects showed a main effect of memory, $F(1.145)=28.564, p<.001$, in which subjects performed generally better on the cued recall memory test than the free recall. There was also a significant Memory $\times$ Advert interaction, $F(1.145)=48.1, p<.001$. This showed that health adverts were remembered significantly better on the cued-recall test in comparison to non-health adverts $(F(1.147)=17.04, p<.001)$. On the other hand, non-health adverts were remembered significantly better on the free-recall test in comparison to

Table 1. Mean memory test scores for health and non-health advertisements.

\begin{tabular}{cccccccccc}
\hline & \multicolumn{4}{c}{ Health programme } & \multicolumn{3}{c}{ Non-health programme } \\
\cline { 2 - 9 }$N=149$ & \multicolumn{2}{c}{ Health Ad } & \multicolumn{2}{c}{ Non-health Ad } & \multicolumn{2}{c}{ Health Ad } & \multicolumn{2}{c}{ Non-health Ad } \\
\cline { 2 - 10 } & $M$ & $S D$ & $M$ & $S D$ & $M$ & $S D$ & $M$ & $S D$ \\
\hline Free recall & 6.35 & 3.44 & 8.28 & 2.82 & 5.58 & 2.61 & 7.85 & 3.69 \\
Cued recall & 9.73 & 3.03 & 7.44 & 2.25 & 9.19 & 2.52 & 7.79 & 3.24 \\
\hline
\end{tabular}


health adverts $(F(1.147)=16.39, p<.001)$. Data also found a significant difference between free and cued recall for health advertisements, $t(75)=-9.035, p<.001$, in which subjects performed significantly worse on the free recall condition than the cued recall condition. No significant differences in memory measure scores were present for non-health advertisements (see Figure 1).

As the free recall and cued recall questionnaires caused a bias towards improved memory for a specific advertisement condition, an average memory score was calculated ([free recall + cued recall]/2). The average memory score, which will be referred to as Global Recall, will now be used for any further analysis.

Tests of between-subjects effects showed no significant main effects for either the Programme or Advert conditions. Furthermore, no significant Programme $\times$ Advert interaction was present. However, although not significant, improved memory was found for health programme-advert congruity, whilst memory was the most impaired for health programme-advert incongruity. There was also no difference in memory for adverts during the non-health programme condition (see Figure 2).

\subsection{Programme Evaluations}

\subsubsection{Programme Evaluation Factors}

Subjects' programme evaluations underwent factor analysis with VARIMAX rotation. This reduced the 14 evaluation dimensions to four significant factors. The four rotated factors explained $65.97 \%$ of the variance. The factor labelled Entertaining (37.28\% of variance) was identified by seven items; Amusing ( $11.81 \%$ of variance) defined by two items; Happy (9.13\% of variance) defined by two items; and complicated ( $7.75 \%$ of variance) defined by three items (see Table 2).

\subsubsection{Programme Evaluation Differences}

Health and non-health programme ratings were compared on the four rotated programme-evaluation factors, to check for any differences. Analysis of Variance found that the non-health programme scored significantly higher than the health programme within the "Entertaining" dimension, $F(1.147)=8.87, p=.003$ as well as the "Happy" dimension, $F(1.147)=31.55, p<.001$ (see Table 3).

Analysis of Covariance (ANCOVA) was used to control for health and non-health programme evaluation differences. Programme evaluation differences had no significant impact on memory for advertisements.

\subsubsection{Programme Involvement}

Furthermore, H3 claimed that high involvement would be detrimental to memory. Pearson Correlations found that programme involvement was negatively correlated with global recall performance in the health programme

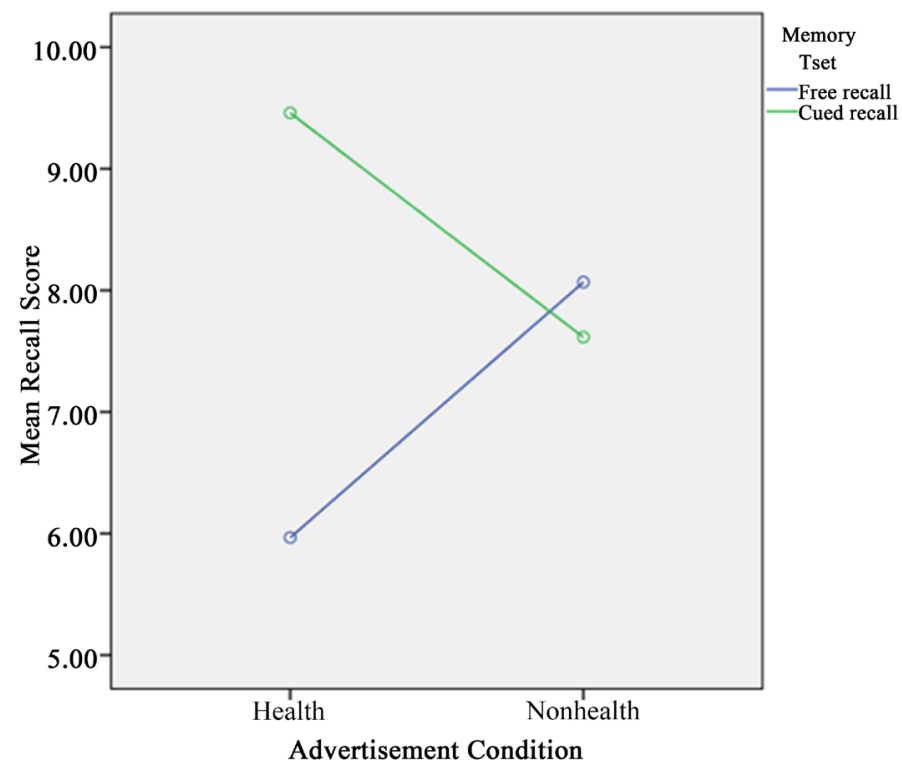

Figure 1. Advertisement $\times$ memory interaction. 


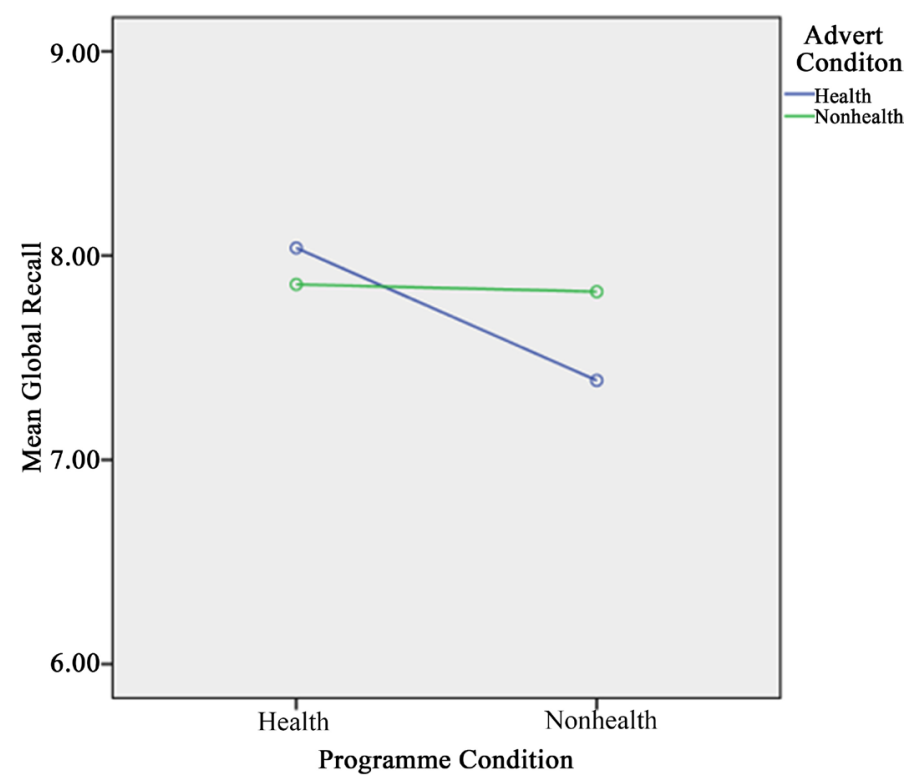

Figure 2. Programme $\times$ advert interaction.

Table 2. Programme-evaluation factors.

\begin{tabular}{ccccc}
\hline & & Loadings of the 14 dimensions on the four factors & \\
\cline { 2 - 4 } & Entertaining & Humorous & Happy & .28 \\
\hline Exciting & .76 & .09 & .13 & .18 \\
Interesting & .75 & -.03 & .28 & .14 \\
Absorbing & .74 & .07 & .20 & -.02 \\
Entertaining & .72 & .21 & .10 & .31 \\
Engaging & .64 & .30 & .14 & -.21 \\
Stimulating & .62 & .19 & .09 & .10 \\
Enjoyable & .47 & .45 & .37 & -.05 \\
Humorous & .11 & .87 & .07 & .05 \\
Amusing & .16 & .85 & .12 & -.01 \\
Happy & .23 & .00 & .90 & .10 \\
Cheerful & .21 & .27 & .81 & .70 \\
Complicated & -.19 & -.15 & .17 & .70 \\
Involving & .41 & .19 & -.03 & .61 \\
Thought-provoking & .45 & .06 & -.08 & 1.09 \\
Eigenvalue & 5.22 & 1.65 & 9.13 & 7.75 \\
Variance (\%) & 37.28 & 11.81 & \\
\hline
\end{tabular}

condition $(r=-.192, p=.091)$ and the non-health condition $(r=-.014, p=.906)$ though this was not significant, hence did not interfere with memory performance.

\subsection{Predictors of Memory for Advertisements}

Personal details and memory for advertisements.

Pearson correlations and univariate analyses found no significant predictors of memory for advertisements. 
Table 3. Means and standard deviations of the four programme evaluation factors.

\begin{tabular}{|c|c|c|c|c|}
\hline \multirow{3}{*}{ Evaluative item } & \multicolumn{4}{|c|}{ Programme conditions } \\
\hline & \multicolumn{2}{|c|}{ Health } & \multicolumn{2}{|c|}{ Non-health } \\
\hline & $M$ & $S D$ & $M$ & $S D$ \\
\hline Entertaining & 4.12 & 1.03 & 4.65 & 1.14 \\
\hline Humorous & 4.23 & 1.40 & 4.43 & 1.09 \\
\hline Happy & 3.44 & 1.06 & 4.56 & 1.37 \\
\hline Involving & 3.74 & 1.29 & 3.69 & .96 \\
\hline
\end{tabular}

\section{Discussion}

In this study three hypotheses were investigated, in which all were rejected. Results showed primarily three things: Health adverts embedded within a health programme were not remembered significantly better than non-health adverts. Hence, no congruity effect was presented, rejecting H1. Health adverts embedded within a non-health programme, or non-health adverts embedded within a health programme, were not remembered significantly better than had they been embedded within a health or non-health programme, respectively. Hence, no incongruence effect was present, rejecting H2. Furthermore, programme involvement had no effect on memory for advertisements, rejecting $\mathrm{H} 3$.

Results from the mixed-model ANOVA found a main effect of memory: subjects performed significantly better on the cued recall memory test than free recall. The Memory $\times$ Advert interaction revealed that on the free recall test, non-health adverts were remembered significantly better than health adverts. However, on the cued recall test, health adverts were remembered better than non-health adverts. The poor performance on free recall for health adverts may have been due to the novelty of the adverts seen, where these adverts were not very familiar to the subjects and not items they would be exposed to daily or even use. Pieters, Warlop and Wedel (2002) found that brand memory recall was much better for adverts that had greater levels of originality and familiarity. In this case, products and brands within non-health adverts were familiar to subjects, but remained original and not before seen. Health adverts were also original; though less familiar to subjects, hence could be the cause for poor free recall performance. Differences in free and cued recall performance is not an unusual finding, as it has been the case in previous research. Furnham and Mainaud (2010) found that their subjects performed better on the free recall test, than they did on the cued recall. Furthermore, Furnham et al. (2002a) also found a significant advertisement type effect for both free recall, in which memory for advertisements was better for car advertisements than food advertisements, and cued recall, in which the opposite was true. Hence, it can be supported that memory for advertisements may be dependent on the memory measure used. Alternatively, as found by Gunter et al. (2002), some advertisements may be much more memorable than others, and may be perceived as more engaging and interesting. It could be suggested that the health advertisements were not as memorable as the non-health advertisements, because they were not as interesting or involving, which could have impaired memory. Although advert evaluations were piloted beforehand, and were specifically selected from a pool of adverts according to similarities in evaluation ratings, it may still be useful in future to embed an advert evaluation questionnaire after the completion of the memory measures.

Furthermore, for health adverts, subjects performed significantly better on the cued recall test than the free recall test, which was not found to be the case within the non-health adverts. This shows that the free recall test was much more difficult for health advertisements than all other conditions. This could be due to the difficult names of new brands that subjects may not have ever heard of before, such as "Mobia by Nautilus” and "Jenny Craig weight loss", in comparison to "BMW" and "Sony Ericsson" in the non-health advert condition. In order to consider both memory measures, and to remove any bias or advert preference each memory measure had, an average/global memory measure was calculated for further investigation.

Our results found no significant Programme $\times$ Advert interaction, which rejects both the cognitive priming theory, as demonstrated by (Furnham et al., 2002a; Gunter et al., 2005; Kamins et al., 1991) the cognitive interference theory (Furnham et al., 1998; Furnham et al., 2002b; Gunter et al., 2002), and contrast effects (Goodstein, 1993; Hunt, 1995). Although results did not turn out significant, there was an advantage for memory of 
health advertisements when they were embedded within a health programme, in comparison to if they were embedded within a non-health programme. On the other hand, memory for non-health advertisements produced similar recall scores for both health and non-health programme conditions, both of which were incongruent with the non-health advertisement content.

Although our results did not present a significant Programme $\times$ Advert interaction, other research has also found similar results. For example, Furnham and Mori (2003) attempted to replicate the findings presented by Furnham et al. (1998), however failed to present a significant interaction. Parker and Furnham (2007) found no interaction between programme-and advert-type conditions, suggesting that the presence or lack of congruity had no effect on memory for sexual or non-sexual advertisements, especially where brand recall is involved. A similar non-significant interaction was also found for another experiment exploring the theme of sex on memory for adverts (Furnham \& Mainaud, 2010). Similarly, our research was unable to support the notion of congruity or incongruity effects, whereby memory for advertisements are strengthened or weakened, respectively, when embedded within a programme of similar content. It could be suggested that the cognitive priming theory and cognitive interference theory do not apply to the theme of health and fitness, or they do not apply to a broad genre in general, in comparison to if the programmes and adverts were a specific "mood setter", such as violence and humour, or alternatively a specific product type, such as food and cars. This study was focussed on a large genre of health, in which adverts covered a range of products such as gym equipment, health supplements and dietary food.

Furthermore, the results of this experiment can contribute to the findings suggested by Harris et al. (2009), where healthy adverts exhibited no effect on food consumption behaviours, unlike non-healthy adverts. In the case of this present study, it can be shown that it may be much more difficult to prime for healthy behaviours, even after context effects have been introduced, which have been shown to facilitate memory for advertisements.

Ratings of audience involvement within the health and non-health programmes were negatively correlated with advertisement global recall, although the former formed a stronger relationship. However, this involvement variable was not significantly associated with memory for advertisements in either condition (Furnham et al., 1998; Furnham \& Mori, 2003; Gunter et al., 2002). It can be concluded that involvement was not an important indicator of advertisement recall.

This study had some methodological limitations that need to be addressed. Conducting the experiment on a large group of subjects simultaneously raises concern for the ability to control for any extraneous variables, such as talking amongst each other. Secondly, as subjects did not know that their memory would be tested on the advertisements, it could be plausible to say that their attention levels may have dropped during advertisements due to boredom, especially if adverts were not comical or involving. For example, Wallace, Vodanovich and Restino (2003) found a high positive correlation between boredom proneness and cognitive failure scores. In order to ensure subjects pay attention to adverts, future research may inform that an advert evaluation questionnaire will take place after the programme. However, in doing so this will reduce ecological validity further and this "laboratory setting" will be farther from representing a "real life setting". Furthermore, evidence has also shown that increased programme-viewing attention hinders memory for advertisements in "laboratory settings", however helps facilitate it in "real-life settings" as a cause of selective exposure (Moorman, Neijens, \& Smit, 2007), whereby one automatically attends to information that they favour, whilst ignoring information that contradicts their views and beliefs (Frey, 1986).

\section{Conclusion}

Overall, the results suggest that programme context does not necessarily facilitate memory for advertisements. In order to stimulate memory for advertisements the advert-programme congruity may have to be narrowed down to a specific product type, or alternatively the concept of programme involvement may interfere with memory for ads embedded within the genres of violence, sex, humour or cartoons (Gunter et al., 2005; Furnham et al., 1998; Furnham \& Mori, 2003; Parker \& Furnham, 2007).

\section{References}

Anderson, C. A., \& Bushman, B. J. (2002). The Effects of Media Violence on Society. Science, 295, 2377-2379. http://dx.doi.org/10.1126/science.1070765 
Bridges, S., \& Thompson, J. (2010). Children’s BMI, Overweight and Obesity. Health Survey for England, 1-21. http://www.hscic.gov.uk/catalogue/PUB03023/heal-surv-eng-2010-resp-heal-ch11-chil-bmi.pdf

Bryant, J., \& Zillmann, D. (1994). Media Effects-Advances in Theory and Research. Hillsdale, NJ: Erlbaum.

Bushman, B. J., \& Bonacci, A. M. (2002). Violence and Sex Impair Memory for Television Adverts. Journal of Applied Psychology, 87, 557-564. http://dx.doi.org/10.1037/0021-9010.87.3.557

De Pelsmacker, P., Geuens, M., \& Anckaert, P. (2002). Media Context and Advertising Effectiveness: The Role of Context Appreciation and Context/AD Similarity. Journal of Advertising, 31, 49-61.

http://dx.doi.org/10.1080/00913367.2002.10673666

Dixon, H. G., Scully, M. L., Wakefield, M. A., White, V. M., \& Crawford, D. A. (2007). The Effects of Television Advertisements for Junk Food versus Nutritious Food on Children's Food Attitudes and Preference. Social Science and Medicine, 65, 1311-1323. http://dx.doi.org/10.1016/j.socscimed.2007.05.011

Frey, D. (1986). Recent Research on Selective Exposure to Information. Advances in Experimental Social Psychology, 19, 41-80. http://dx.doi.org/10.1016/S0065-2601(08)60212-9

Furnham, A., Bergland, J., \& Gunter, B. (2002a). Memory for Television Advertisements as a Function of AdvertisementProgram Congruity. Applied Cognitive Psychology, 16, 525-545. http://dx.doi.org/10.1002/acp.812

Furnham, A., Gunter, B., \& Richardson, B. (2002b). Effects of Product-Program Congruity and Viewer Involvement on Memory for Televised Advertisements. Journal of Applied Social Psychology, 1, 124-141. http://dx.doi.org/10.1111/j.1559-1816.2002.tb01423.x

Furnham, A., Gunter, B., \& Walsh, D. (1998). Effects of Programme Context on Memory of Humorous Television Commercials. Applied Cognitive Psychology, 12, 555-567. http://dx.doi.org/10.1002/(SICI)1099-0720(1998120)12:6<555::AID-ACP537>3.0.CO;2-X

Furnham, A., \& Mainaud, L. (2010). The Effect of French Television Sexual Program Content on the Recall of Sexual and Nonsexual Advertisements. Journal of Sex Research, 47, 1-9.

Furnham, A., \& Mori, T. (2003). The Effect of Programme Context on Memory for Humorous Television Advertisements in Japan. Psychologia, 46, 53-66. http://dx.doi.org/10.2117/psysoc.2003.53

Goodstein, R. C. (1993). Category-Based Applications and Extensions in Advertising: Motivating More Extensive AD Processing. Journal of Consumer Research, 20, 87-99. http://dx.doi.org/10.1086/209335

Gorn, G. J., \& Goldberg, M. E. (1982). Behavioural Evidence of the Effects of Televised Food Messages on Children. Journal of Consumer Research, 9, 200-205. http://dx.doi.org/10.1086/208913

Gunter, B., Baluch, B., Duffy, L., \& Furnham, A. (2002). Children’s Memory for Television Advertising: Effects of Program-Advertising Congruency. Applied Cognitive Psychology, 16, 171-190. http://dx.doi.org/10.1002/acp.776

Gunter, B., Clifford, B. R., \& Berry, C. (1980). Release from Proactive Interference with Television News Items: Evidence for Encoding Dimensions within Televised News. Journal of Experimental Psychology: Human Learning and Memory, 6, 216-223. http://dx.doi.org/10.1037/0278-7393.6.2.216

Gunter, B., Furnham, A., \& Pappa, E. (2005). Effects of Television Violence on Memory for Violent and Nonviolent Advertising. Journal of Applied Social Psychology, 35, 1680-1697. http://dx.doi.org/10.1111/j.1559-1816.2005.tb02190.x

Harris, J. L., Bargh, J. A., \& Brownell, K. D. (2009). Priming Effects of Television Food Advertising on Eating Behavior. Health Psychology, 28, 404-413. http://dx.doi.org/10.1037/a0014399

Hastings, G., Stead, M., McDermott, L., Forsyth, A., MacKintosh, A. M., \& Rayner, M. et al. (2003). Review of Research on the Effects of Food Promotion to Children. Report Prepared for the UK Food Standards Agency. Centre for Social Marketing, University of Strathclyde, Glasgow.

Hirani, V. (2010). Adult Anthropometric Measures, Overweight and Obesity. Health Survey for England, 1-26. http://www.hscic.gov.uk/catalogue/PUB03023/heal-surv-eng-2010-resp-heal-ch10-adul-anth.pdf

Howard, J. (1977). Consumer Behaviour: Application and Theory. New York: McGraw-Hill.

Hunt, R. R. (1995). The Subtlety of Distinctiveness: What von Restorff Really Did. Psychonomic Bulletin and Review, 2, 105-112. http://dx.doi.org/10.3758/BF03214414

Juntunen, A. (1995). Media Context and Advertising Processing. Helsinki: Helsinki School of Economics and Business Administration.

Kamins, M. A., Marks, L. J., \& Skinner, D. (1991). Television Commercial Evaluation in the Context of Program-Induced Mood: Congruity versus Consistency Effects. Journal of Advertising, 20, 1-14. http://dx.doi.org/10.1080/00913367.1991.10673209

McNair, D., Lorr, M., \& Doppleman, L. (1971). POMS Manual for the Profile of Mood States. San Diego, CA: Educational and Industrial Testing Service. 
Meyers-Levy, J., \& Tybout, A. M. (1997). Context Effects at Encoding and Judgment in Consumption Settings: The Role of Cognitive Resources. Journal of Consumer Research, 24, 1-14. http://dx.doi.org/10.1086/209490

Moorman, M., Neijens, P., \& Smit, E. (2007). The Effects of Program Involvement on Commercial Exposure and Recall in a Naturalistic Setting. Journal of Advertising, 36, 121-137. http://dx.doi.org/10.2753/JOA0091-3367360109

Norris, C. E., \& Colman, A. M. (1992). Context Effects on Recall and Recognition of Magazine Advertisements. Journal of Advertising, 21, 37-46. http://dx.doi.org/10.1080/00913367.1992.10673374

Norris, C. E., \& Colman, A. M. (1993). Context Effects on Memory for Television Advertisements. Social Behaviour and Personality: An International Journal, 21, 279-296. http://dx.doi.org/10.2224/sbp.1993.21.4.279

Parker, E., \& Furnham, A. (2007). Does Sex Sell? The Effect of Sexual Programme Content on the Recall of Sexual and Non-Sexual Advertisements. Applied Cognitive Psychology, 21, 1217-1228. http://dx.doi.org/10.1002/acp.1325

Pieters, R., Warlop, L., \& Weder, M. (2002). Breaking through the Clutter: Benefits of Advertisement Originality and Familiarity for Brand Attention and Memory. Management Science, 48, 765-781. http://dx.doi.org/10.1287/mnsc.48.6.765.192

Sanbonmatsu, D. M., \& Fazio, R. H. (1991). Construct Accessibility: Determinants, Consequences and Implications for the Media. In J. Bryant, \& D. Zillmann (Ed.), Responding to the Screen: Reception and Reaction Processes (pp. 45-62). Hillsdale, NJ: Erlbaum.

Hancox, R. J., Milne, B. J., \& Poulton, R. (2004). Association between Child and Adolescent Television Viewing and Adult Health: A Longitudinal Birth Cohort Study. The Lancet, 364, 257-262. http://dx.doi.org/10.1016/S0140-6736(04)16675-0

Viner, R. M., \& Cole, T. J. (2005). Television Viewing in Early Childhood Predicts Adult Body Mass Index. Journal of Pediatrics, 147, 429-435. http://dx.doi.org/10.1016/j.jpeds.2005.05.005

Wallace, J. C., Vodanovich, S. J., \& Restino, B. M. (2003). Predicting Cognitive Failures from Boredom Proneness and Daytime Sleepiness Scores: An Investigation within Military and Undergraduate Samples. Personality and Individual Differences, 34, 635-644. http://dx.doi.org/10.1016/S0191-8869(02)00050-8

Watson, D., \& Clark, L. A. (1999). The PANAS-X: Manual for the Positive and Negative Affect Schedule-Expanded Form. http://www.psychology.uiowa.edu/Faculty/Watson/Watson.html

\section{Submit or recommend next manuscript to SCIRP and we will provide best service for you:}

Accepting pre-submission inquiries through Email, Facebook, LinkedIn, Twitter, etc.

A wide selection of journals (inclusive of 9 subjects, more than 200 journals)

Providing 24-hour high-quality service

User-friendly online submission system

Fair and swift peer-review system

Efficient typesetting and proofreading procedure

Display of the result of downloads and visits, as well as the number of cited articles

Maximum dissemination of your research work

Submit your manuscript at: http://papersubmission.scirp.org/ 